\title{
THE IMPACT OF URBAN EXPANSION ON AGRICULTURAL LAND USE CHANGES IN ALIGARH, UTTAR PRADESH, INDIA
}

\author{
Sadaf Khan ${ }^{1, *}$, Himanchal $^{1}$ \\ Interdisciplinary Department of Remote Sensing and GIS Applications, \\ Aligarh Muslim University, Aligarh, India \\ *khan.sadafk123@gmail.com
}

KEYWORDS: Land use changes, Agriculture, Food security, Climate change, Urban sprawl.

\begin{abstract}
India's urbanization has resulted in a significant change in many regions for both agricultural land and agricultural land use. However, there is limited understanding about the relationship between the two primary changes occurring to India's agricultural land - the urban expansion on agricultural land and agricultural land use intensity. Our primary goal here is to examine agricultural land change patterns and processes, and their main driving forces in Aligarh region (Uttar Pradesh) during the time periods from 2011 to 2018. We have conducted a remote sensing and GIS based analysis of change pattern using multi-temporal Landsat imageries for the years 2011 and 2018 by investigating the magnitude of changes in agricultural land use intensity across the district in a geographical perspective. Our study captured gradual decrease in the agricultural land in Aligarh district. The results also show that urban expansion is associated with a decline in agricultural land use intensity. The region experienced agriculture transition, and the urban expansion trend persisted till 2018. In terms of the drivers, we believe that the population and economic factors are most influential in shaping urban centers, while lower incentive and climatic shifts are the key drivers of decrease in agricultural land. Our study highlights the drastic effects of socio-economic and climatic changes on links between urbanization, and agricultural land which implies that urban land expansion is highly likely in future and consequently, will create pressure on the country's food security.
\end{abstract}

\subsection{INTRODUCTION}

Urban sprawl is a progressive characteristic of the built environment in densely populated countries. In many developing countries, urban sprawl is happening at a faster pace due to rapid economic growth and population dynamics tied with globalization [1]. According to the United Nation recent statistics, about $54 \%$ of the world's population lives in urban areas, the predicted rate by 2050 is a $12 \%$ increase than the present level [2]. Urban sprawl is often linked with the idea of an unfitting development. Irrational urban sprawl in developing nations has many adverse effects on agricultural sector. Often agriculture land use has to make significant adjustments because of rapid urban and industrial growth [3]. However with planned sprawl, smart cities can be built.

It is noticed that cities expanded in geographic size faster than they grew in population [4]. Likewise in many developing nations, such as India, also experiencing unprecedented and unplanned developmental activities in cities due to the rapid population growth and migratory behavior of youth searching jobs in city centers. Agricultural lands in India are facing serious threat from growing urban centers, which has resulted in rapid but skewed urbanization.

Unplanned urbanization have large scale impacts on physical health and environmental setting, particularly, on waste disposal and sanitary solutions. It is necessary to monitoring and modeling the land use / cover of the city over time not only for better urban planning, but also for managing land resources.

Monitoring land use changes system using satellite imageries has been gaining attraction since last two decades. Remote sensing systems along with spatial analysis techniques like geographical information system (GIS) can be used for the monitoring and urban planning as they enable the reporting of overall sprawl at a detailed level. Archived remote sensing data is an important source of information on past land use / cover changes that can be used to map and monitor the urban sprawls. Since the launch of Landsat-1 (ERTS) satellites, territorial mapping has come a long way over last three decades. Today a wide variety of satellite imageries with varying resolutions and capacity are available for mapping and modeling sprawl changes and future predictions. Remote sensing and GIS techniques have been utilized in order to map and monitor urban growth in the Aligarh City, India using multi- temporal datasets. Challenges arises from climate change and environmental conditions, along with population dynamics and economic impacts has to be considered carefully for decision makers and regional and urban planners especially in the context of growing cities.

\subsection{STUDY AREA}

This work has been analysed the land use changing pattern in Aligarh city. The city of Aligarh is situated on the western part of the state of Uttar Pradesh, India (Fig.1) occupying a small part of Ganga - Yamuna doab between the latitude $27^{\circ} 35^{\prime}$ and $28^{\circ} 10^{\prime} \mathrm{N}$ and $77^{\circ} 29^{\prime}$ and $78^{\circ} 36^{\prime} \mathrm{E}$ longitudes falling in Survey of India toposheet number 53H, 53L \& 54E. The northern boundary of the district is contiguous with that of Bulandshahar district. Ganga river forms the natural boundary between Aligarh and Budaun in the north eastern corner of the district whereas the Yamuna in the northwest forms the state boundary between Uttar Pradesh \& Haryana. It is located $145 \mathrm{~km}$ southeast of Delhi and $307 \mathrm{~km}$ northeast of Kanpur in the western region of Uttar Pradesh. The city was initially established as a Koil fort in the 12th century and was taken by the British in 1803. The remains of prehistoric fort at a standstill the distance of $3 \mathrm{~km}$ north of Aligarh city. The study area is located in Koil tahsil of Aligarh district. The city is administrative headquarters of the district and agricultural trade center. The study area municipal limit as notified in 1955 is $31.57 \mathrm{~km}^{2}$. The Aligarh district Percentage decadal variation in population is 12.45 in 1951, 22.16 in 1981, 29.95 in 1991 and decreasing in 22.08 in 2001. The population of Aligarh in 1901

* Corresponding author 
is given as 70127. It has since increased progressively to 669,087 in 2001 , and expected to be $10,37,418$ in 2021. As per the census record, the population of Aligarh in 2011 was 874,408 which have increased to $1,240,896$ in 2017 . It is one of the largest cities in Uttar Pradesh having an area of $40.722 \mathrm{~km}^{2}$. The normal annual rainfall is observed to be $708.7 \mathrm{~mm}$. The maximum rainfall occurs during the monsoon period i.e., June to September. July is the wettest month. Aligarh experiences the tropical monsoon type of climate. Agricultural product processing and manufacturing plays an important role in the economy of the city. It is an important business center of the state and is mainly famous for its lock industry which was first established in 1870 . With increase in urban sprawl around city, agricultural area has changed considerably, grasslands have been cleared and converted into new settlement colonies. The summer and winters are severe. Maximum temperature shoots up to $45^{\circ} \mathrm{C}$ during May and minimum temperature remains around $18^{\circ} \mathrm{C}$. Average maximum temperature remains around $42^{\circ} \mathrm{C}$ during May. In the winter seasons the temperature rests around $21^{\circ} \mathrm{C} \&$ minimum temperature remains around $5^{\circ} \mathrm{C}$. Rainy season commences in the middle of June \& continues till September. The average relative humidity experienced in the morning is $62.25 \%$ and in the evening the recordings decrease to $44.2 \%$. The wind velocity ranges between 4.6 and 9.3 $\mathrm{Kms} / \mathrm{hr}[5]$. Topographically, the area is almost open plain, sloping gently from north to south in the western side \& north west to west in the eastern side. The highest elevation of the district is 195.072 mamsl (Meters above mean sea level) and the lowest is 173.76 mamsl. The average gradient of land surface is $2 \mathrm{~cm} / \mathrm{km}$. Geomorphologically, the district can be grouped into three geomorphic units as detailed below: (i) Recent flood plain of stream - yellow colored clay, silt and sand of various grades, (ii) Terrace Zone - yellow and grey colored silt, sand and kankar beds and (iii) older Alluvial Plains - yellow grey colored silt, sand and kankar beds.

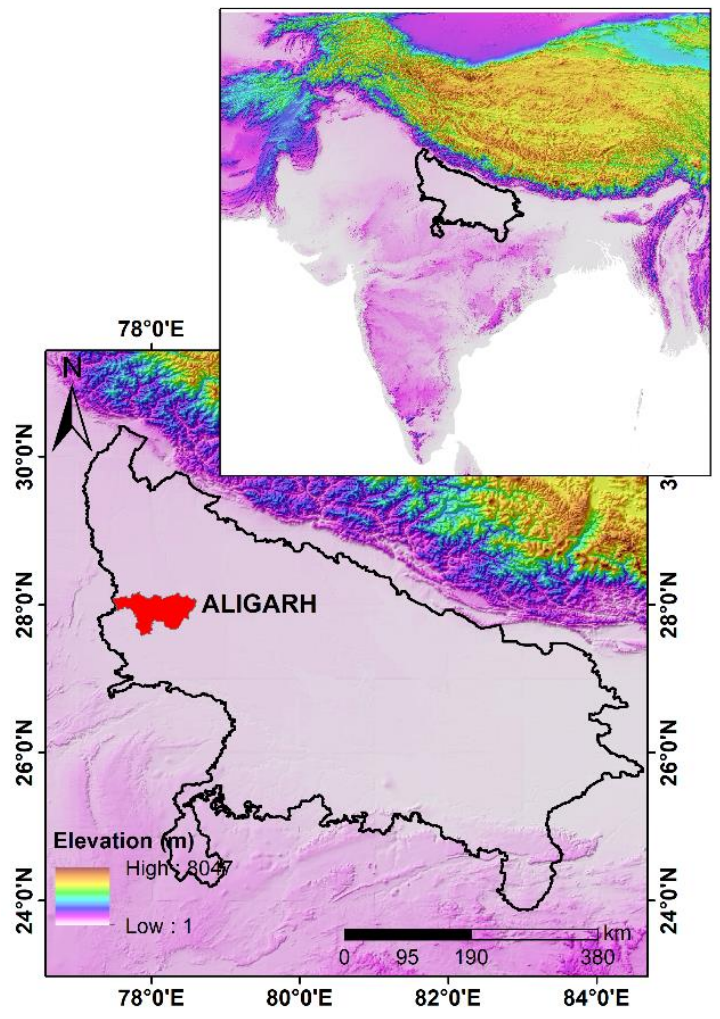

Fig 1. Location map of the study area i.e. Aligarh district.

\subsection{DATA AND METHODS}

The dataset required for LULC (Land use and Land cover) analysis were collected from Landsat-8 OLI satellite via USGS Earth Explorer website. For temporal analysis, satellite imageries of two time period were taken to perform the classification. The urban sprawls were mapped using Aligarh city boundary data was obtained from the Municipal Corporation of Aligarh which contains municipal boundaries of the city. Demographic data of the study area was collected from the published report of Directorate of Census Operation, Census of India.

We obtained land use land cover map for the study area using supervised classification techniques applied in Erdas Imagine 9.2 v. software and ArcGIS 10.3 v. LULC (Land use Land cover) features were extracted from both 2011 and 2018 images. We used maximum likelihood supervised techniques in this study. The raster files, generated in Erdas Imagine 9.2 results were then converted into shape file (.shp). These shape files were then used in ArcGIS software for area calculations and change detection analysis.

\subsection{RESULTS}

Table 1 presents the changing land use land cover for the period between 2011 and 2018. It can be clearly seen from the Table 1 that the built up areas are tremendously increased from 2611 hectares to 5336 hectares in about 7 years. This increase has largely destroyed the agricultural land and plantations in Aligarh City. It can also be noticed that considerable amount of agriculture (about 1349 hectares) and plantation has lost (about 1352 hectares) its space over 7 years.

\begin{tabular}{|l|l|l|}
\hline \multirow{2}{*}{ CLASS } & \multicolumn{2}{|l|}{ AREA (in hectares) } \\
\cline { 2 - 3 } & $\mathbf{2 0 1 1}$ & $\mathbf{2 0 1 8}$ \\
\hline BUILT UP & 2644.11 & 5336.1 \\
\hline WATER BODIES & 74.88 & 84.4425 \\
\hline VEGETATION & 5139.36 & 3787.418 \\
\hline AGRICULTURAL LAND & 15131.36 & 13781.75 \\
\hline
\end{tabular}

Table 1. Land use changes between 2011 and 2018

Figure 2 and 3 show the land use and land cover mapped using supervised classification (maximum likelihood) techniques for the study area between the period $2011-2018$.

The total sprawl calculated in 2011 is $17.05 \mathrm{~km}^{2}$ and for the year 2018 it is calculated as $22 \mathrm{~km}^{2}$ as depicted in Figure 3 and 4 and mentioned in Table 2.

\begin{tabular}{|l|c|}
\hline YEAR & $\begin{array}{l}\text { URBAN SPRAWL } \\
\text { AREA (in km }{ }^{2} \text { ) }\end{array}$ \\
\hline $\mathbf{2 0 1 1}$ & 17.05 \\
\hline $\mathbf{2 0 1 8}$ & 22 \\
\hline Change & 4.95 \\
\hline
\end{tabular}

Table 2. Urban sprawl in square kilometer for Aligarh City

\begin{tabular}{|l|c|}
\hline YEAR & $\begin{array}{c}\text { POPULATION } \\
\text { (in lakhs) }\end{array}$ \\
\hline $\mathbf{2 0 0 6}$ & 7.89 \\
\hline $\mathbf{2 0 1 1}$ & 8.74 \\
\hline $\mathbf{2 0 1 8}$ & 12.4 \\
\hline Change (2011-2018) & 3.66 \\
\hline
\end{tabular}

Table 3. Population census data for Aligarh. 


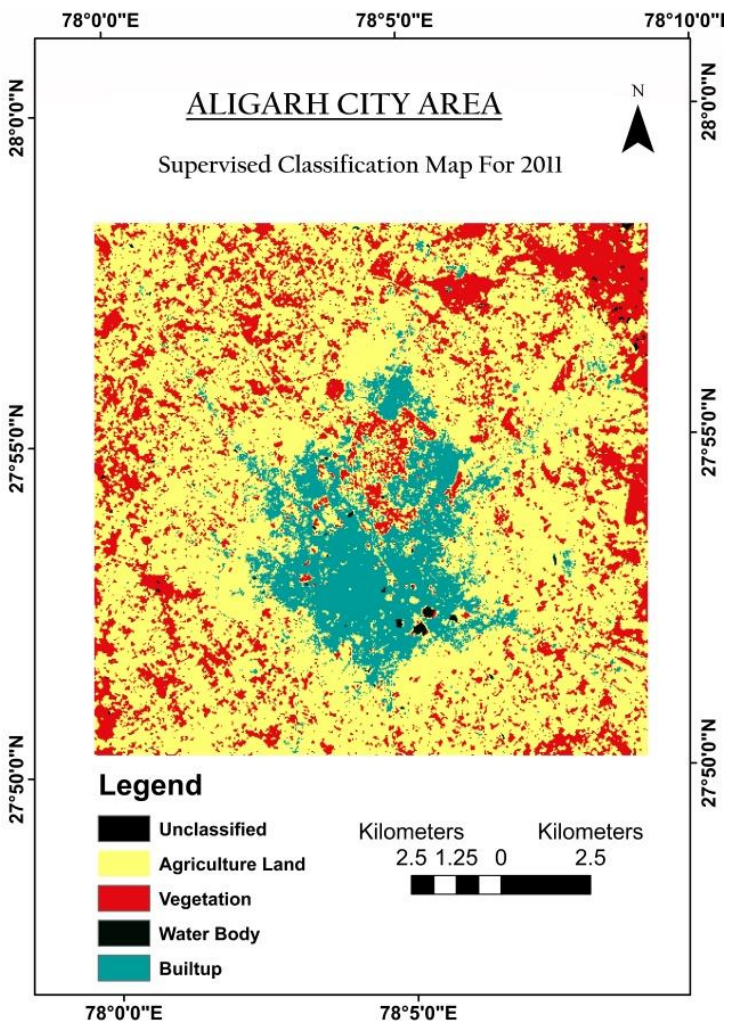

Fig 2. Land use map obtained from supervised classification of 2011 Landsat TM imagery.

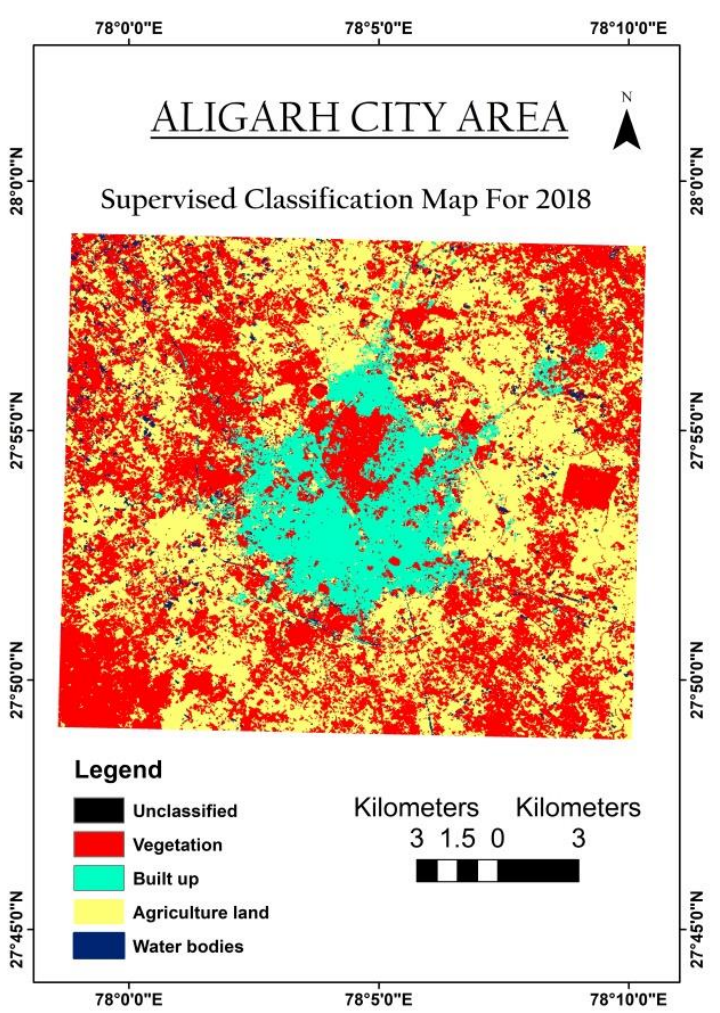

Fig 3. Land use map obtained from supervised classification of 2018_Landsat TM imagery.

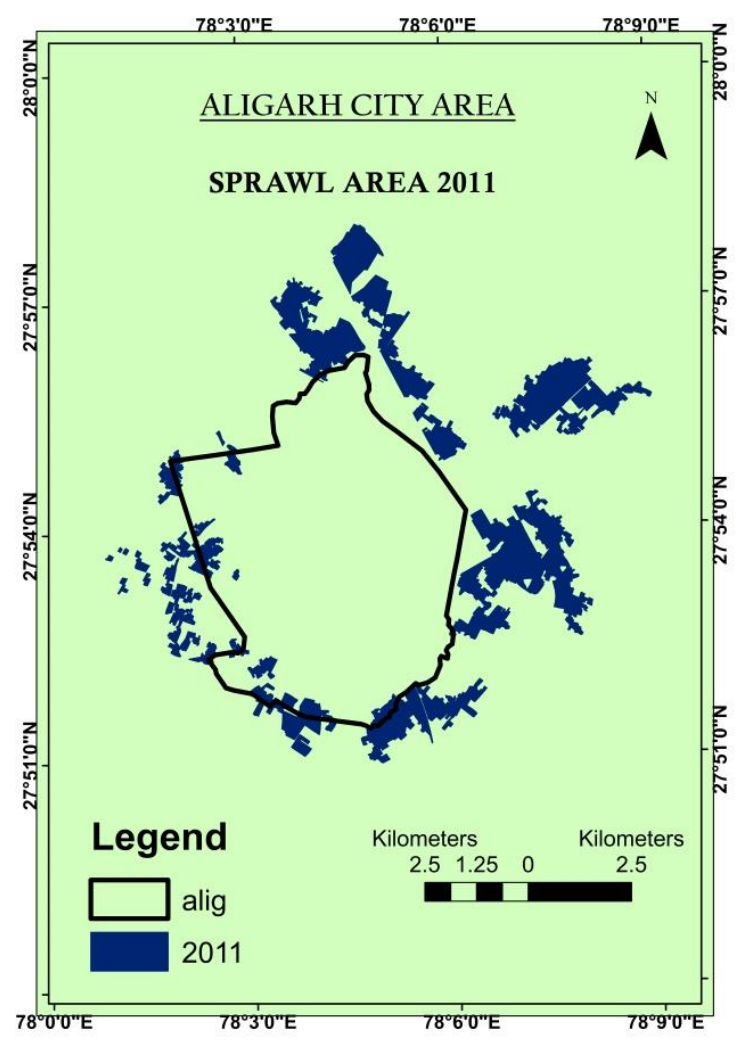

Fig 4. Urban sprawl mapped for the year 2011.

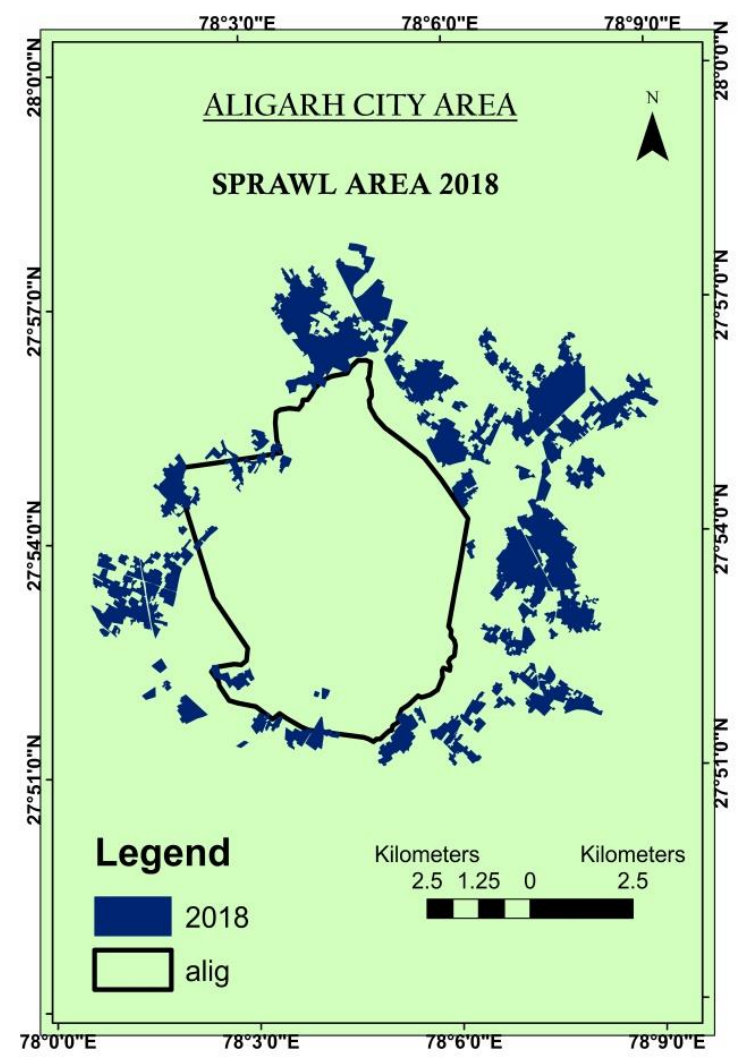

Fig 5. Expanded urban sprawl mapped for 2018.

The change in population between 2011 and 2018 is about 3.66 lakh person. Considering the large scale growth in population, 
the increased urban sprawl of about $4.95 \mathrm{~km}^{2}$ can be attributed to the population dynamics alone.

\subsection{CONCLUSION}

Mostly land use activity in urban areas spells irreversible changes. The population and economic factors are the most influential in shaping urban centers, while lower incentive and climatic shifts are the key drivers of decrease in agricultural land. This study highlights the drastic effects of socio-economic changes on links between urbanization and agricultural land which implies that urban land expansion is highly likely in future and that increases the pressure on country's food security. Globally we are experiencing population increase all around the urban centers, which ultimately results in the decrease of the agricultural land present on the fringe area of the cities. There is a need to set a balance between present requirements of land against future needs of this growing population. Preserving agricultural land in the fringe area of expanding cities is vital for preserving and maintaining open spaces and therefore, environmental quality. Agricultural lands having lower productivity should be identified with the help our modern technologies available and accommodation for the people needs to be done in such marked areas of low quality lands. As there is a need to control and regulate the development of sprawls in order to control the land use. Remote sensing data coupled with GIS is a versatile tool to generate and handle the large number of data sets which can prove to be of great use in for proper urban and land use planning and its management.

\section{REFERNCES}

Iizuka $\mathrm{K}$ et al. 2017. Modeling Future Urban Sprawl and Landscape Change in the Laguna de Bay Area, Philippines. Land, 6(2), 26. doi:10.3390/land6020026

UN World Urbanization Prospects. 2015. The 2014 Revision (ST/ESA/SER.A/352); Population Division, Department of Economic and Social Affairs, United Nations: New York, NY, USA.

Atu, JE. et al. 2012. The Effects of Urban Sprawl on Peripheral Agricultural Lands in Calabar, Nigeria. International Review of Socal Sciences and Humanities, 2(2), pp. 68-76.

Resnik, D B. 2010. Urban Sprawl, Smart Growth, and Deliberative Democracy. Am J Public Health. 2010 October; 100(10): pp. 1852-1856. doi: 10.2105/AJPH.2009.182501

GROUND WATER BROCHURE OF ALIGARH DISTRICT, U.P.(A.A.P.: 2012-2013) By Saidul Haq Scientist 'B', Central Ground Water Board Northern Region, Lucknow, UP

https://www.un.org/development/desa/pub-lications/2018revision-of-world-urbanization-prospects.html

DIRECTORATE OF CENSUS OPERATI- ONS 2011, Uttar Pradesh, Series 10, Part XII-B Handbook for Aligarh district 